\title{
APROPRIAÇÃO DISCURSIVA DO TEMA 'INTERDISCIPLINARIDADE' POR PROFESSORES E LICENCIANDOS EM FÓRUM ELETRÔNICO*
}

\section{Discursive appropriation of the theme 'interdisciplinarity' by teachers in an electronic forum}

\author{
Flavia Rezende ${ }^{1}$ \\ Glória Regina Pessôa Campello Queiroz ${ }^{2}$
}

Resumo: O contexto deste estudo é um projeto de formação docente que integrou formadores da Universidade, licenciandos em Física e professores de várias disciplinas da escola pública, e que teve como objetivo engajar licenciandos e professores na implementação de um projeto pedagógico interdisciplinar nas escolas. A atividade analisada neste trabalho, parte desse processo, consistiu em um curso no ambiente virtual InterAge e teve como objetivo a solução de uma situação-problema similar à vivenciada nas escolas, com apoio da discussão on-line de textos sobre interdisciplinaridade e a orientação de uma tutora. No presente estudo, analisamos o processo de apropriação discursiva do tema 'interdisciplinaridade' pelos participantes do fórum de discussão. A construção de significados relacionados aos textos variou entre apropriações teóricas, teórico-práticas e exclusivamente práticas. A observação de resistência ao discurso teórico indicou a necessidade de se problematizar a apropriação, por licenciandos, de resultados da pesquisa em Educação em Ciências na formação profissional.

Palavras-chave: Construção de significados. Interações on-line. Interdisciplinaridade. Formação de professores de ciências.

\begin{abstract}
The context of this research was a project that integrated instructors, Physics teachers' education undergraduates and in-service teachers from public high school. In the first phase, the aim was to engage the participants in the implementation of an interdisciplinary project at school. In the second, the group was enrolled in a course delivered by InterAge virtual environment whose purpose was to solve a problem similar to the one they had to cope at school. In the present study, the meaning construction of 'interdisciplinarity' and the process of appropriation of a theoretical discourse by the participants of an on-line forum were analysed. The results point to the necessity of not taking for granted the meanings given by undergraduates to science education theoretical knowledge. The hybrid construction built in the confluence of the languages of natural and social sciences seems not to be favored during the Physics teachers' education course.
\end{abstract}

Keywords: Meaning construction. On-line interactions. Interdisciplinarity. Science teachers' education.

\footnotetext{
* Com apoio do CNPq e FAPERJ.

${ }^{1}$ Licenciada em Física, Doutora em Educação; Docente, Núcleo de Tecnologia Educacional para a Saúde, Universidade Federal do Rio de Janeiro, RJ, Brasil. flaviarezende@uol.com.br

${ }^{2}$ Licenciada em Física, Doutora em Educação; Docente, Instituto de Física, Universidade Estadual do Rio de Janeiro, RJ, Brasil.gloria@uerj.br

${ }^{1}$ Av. Carlos Chagas Filho, 373

Centro de Ciências da Saúde, Bloco A - sala 12

Cidade Universitária - Rio de Janeiro, RJ

21.941-902

459

Ciência $\mathfrak{E}$ Educação, v. 15, n. 3, p. 459-478, 2009
} 


\section{Introdução}

Esta pesquisa se insere em um projeto de formação docente que integrou formadores da Universidade, licenciandos em Física e professores de várias disciplinas da escola pública, articulando, assim, a formação inicial à continuada. Além da parte presencial, realizada em encontros na Universidade e nas quatro escolas envolvidas no projeto, a proposta de formação incluiu um curso a distância, que é o contexto do presente estudo. Nas escolas, o objetivo foi engajar os participantes na implementação de um projeto pedagógico que emergisse da relação entre mais de uma disciplina, configurando-se como um trabalho interdisciplinar, inspirado no tema da Semana Nacional de Ciência e Tecnologia em 2006: "100 anos do 14-BIS". O curso, viabilizado pelo ambiente virtual InterAge ${ }^{3}$ (REZENDE et al., 2003), teve como objetivo propiciar o intercâmbio de experiências entre os participantes e a discussão acadêmica em torno da realidade escolar. Neste sentido, a proposta formativa do InterAge, baseada no modelo de formação de Porlán e Rivero (1998), foi considerada adequada ao projeto por romper com a transmissão de conhecimentos, engajando professores na discussão de problemas reais da prática pedagógica. Os participantes deveriam propor uma solução na forma de planejamento de aulas para uma situação-problema também relacionada à implementação de um projeto pedagógico interdisciplinar na escola, tendo como suporte a discussão em um fórum eletrônico com base na leitura de textos acadêmicos sobre interdisciplinaridade e na orientação de tutores. A distribuição posterior dos participantes em grupos formados preferencialmente por licenciandos e professores, para elaboração do planejamento, propiciaria também a integração das diferentes disciplinas envolvidas.

As interações discursivas viabilizadas pelas ferramentas de comunicação disponíveis nos ambientes virtuais de aprendizagem são fundamentais para a construção do conhecimento, que, de acordo com Vygotsky (1984, p. 64), acontece por meio da "internalização de atividades construídas historicamente e enraizadas socialmente". Com esse entendimento, a pesquisa sobre processos educativos viabilizados por ambientes virtuais vem incorporando a perspectiva sociocultural sob o paradigma Computer Supported Collaborative Learning (KOSCHMAN, 1996), ao se voltar para a compreensão de como a aprendizagem está refletida na linguagem dos aprendizes e como a tecnologia pode ser usada em ambientes colaborativos. Neste sentido, alguns estudos têm tentado modelar a construção colaborativa do conhecimento e têm analisado as interações on-line a partir de métodos quantitativos e qualitativos (MURPHY, 2004; SCHRIRE, 2006; PUNTAMBEKAR, 2006).

A hipótese implícita neste paradigma é a de que as interações on-line podem ser tratadas como interações discursivas no sentido empregado por Bakhtin (2004), isto é, como fenômeno social que constitui fundamentalmente a língua, realizado por meio de "enunciados orais e escritos concretos e únicos proferidos pelos integrantes desse ou daquele campo da atividade humana" (p. 261).

${ }^{3}$ Disponível em: <http://nutes2.nutes.ufrj.br/interage $>$. 
Apropriação discursiva do tema 'interdisciplinaridade' ...

Além da mediação simbólica, que se dá nas trocas discursivas on-line, a mediação técnica das ferramentas de comunicação também conforma o processo. Wertsch (2002) lembra que esta mediação é caracterizada por propriedades novas e cruciais da comunicação social que podem fazer emergir novos processos mentais. Algumas especificidades dos fóruns eletrônicos que poderiam influenciar a comunicação e a construção social do conhecimento seriam (REZENDE e OSTERMANN, 2006): a focalização linguística em detrimento de outras formas de comunicação; a comunicação na forma de enunciados por escrito; os intervalos de tempo entre turnos, que tendem a ser bem maiores que em uma aula presencial; o discurso muito menos linear; o tempo de que o participante dispõe para enunciação, e a possibilidade de consulta a outras pessoas ou a fontes bibliográficas para construir seu enunciado.

No presente estudo, tem-se como objeto as interações discursivas entre licenciandos, professores em serviço e uma tutora em um fórum eletrônico idealizado para proporcionar discussões acerca do conteúdo temático "interdisciplinaridade", preparando os participantes para a elaboração de planejamentos de aulas interdisciplinares. A pesquisa traz contribuições para o corpo de conhecimentos produzido no âmbito do paradigma Computer Supported Collaborative Learning, já que tem como objeto questões relacionadas ao uso da linguagem e à relação social entre participantes de um fórum eletrônico. Ainda que não tenhamos a pretensão de investigar especificamente relações entre os processos mentais e características do meio eletrônico, o estudo tece considerações sobre características do meio eletrônico que possivelmente conformaram a produção do discurso, já que seu contexto de produção é marcado tanto por aspectos sociais quanto tecnológicos.

Por outro lado, sendo o processo educativo investigado desenvolvido no âmbito da formação de professores das ciências naturais, os resultados do trabalho interessam à pesquisa em formação docente. Adotar a perspectiva sociocultural implica conceber os processos de formação de professores como experiências nas quais gêneros de discurso diferentes são colocados em contato. No âmbito da formação inicial e continuada de professores das ciências da natureza, é possível prever o embate entre as perspectivas da teoria e da prática, em geral desarticuladas na formação inicial pela aplicação do modelo da racionalidade técnica nos currículos de formação profissional (SCHNETZLER, 2000). A autora aponta a desarticulação entre as disciplinas científicas, de um lado, e as pedagógicas, de outro, como causadora da ineficiência da formação. Apesar de o currículo prever que a articulação entre elas se dê nas disciplinas de Estágio Supervisionado e Instrumentação para o Ensino, Schnetzler (2000) acredita que "a efetividade da integração entre conteúdos pedagógicos com conteúdos específicos não pode se restringir a essas disciplinas" (p. 20). Desde a década de 1980, Shulman (1987) já apontava a responsabilidade de toda a universidade com a formação docente.

A concepção dos processos formativos enquanto apropriação discursiva parte da inseparabilidade entre pensamento e linguagem e da relação entre as interações sociais e os contextos sociais e culturais, dando ênfase ao discurso dos atores e em como esses discursos conformam a ação (WERTSCH, 1993). O aporte de Bakhtin à abordagem sociocultural permitirá a análise não só do conteúdo envolvido nas interações discursivas, mas também do dialogismo e dos movimentos de apropriação e de resistência a linguagens sociais. A análise de discurso será usada para examinar o encontro entre as vozes do tutor, dos professores, licenciandos, e dos textos acadêmicos sobre interdisciplinaridade no fórum de discussão que serviu como referência para a posterior elaboração de propostas de ensino. Entendendo as intera- 
Rezende, F.; Queiroz, G. R. P. C.

ções sociais e o embate entre diferentes gêneros discursivos como processos constitutivos da formação docente, elegemos a seguinte questão de pesquisa: como se desenvolveu a apropriação de significados teóricos e práticos relacionados ao tema 'interdisciplinaridade', no processo formativo em foco?

\section{O aporte de Bakhtin à perspectiva sociocultural}

$\mathrm{Na}$ perspectiva sociocultural, a educação passa a ser concebida como o processo de tornar um indivíduo capaz de compreender e participar ativamente dos discursos das disciplinas (MERCER, 1998), considerando-se as origens social e cultural dos recursos e modelos lógicos, linguísticos e semióticos aprendidos a partir de parceiros sociais mais experientes. Esta interação social não é idealizada como se mentes autônomas se encontrassem em um parlamento racional de iguais; mas, em vez disso, pauta-se em uma noção mais complexa de aprendizagem na comunidade, frequentemente entre participantes desiguais com um papel significativo atribuído a relações de poder e de diferença de idade, classe, gênero, língua e background cultural (LEMKE, 2001).

Nessa perspectiva, Wertsch (1993) explora a noção de ação com intenção, mediada por ferramentas culturais, que torna indissociável a ação de seus instrumentos mediadores. Wertsch (1993) explora essa unidade de análise com base nas obras de Vygotsky e de Bakhtin, que convergem para a ideia de que para se compreender a ação mental humana, se devem compreender os mecanismos semióticos. Assim, no enfoque da ação mediada, assume-se que determinados aspectos do funcionamento mental humano estão, de acordo com Vygotsky (2001), fundamentalmente ligados à noção de mediação e, portanto, aos processos comunicativos. Alguns exemplos de ferramentas culturais são: a linguagem, os sistemas de cálculo, as técnicas mnemônicas, os esquemas, os diagramas, os mapas, os desenhos, os símbolos convencionais.

Wertsch (1993) se vale das ideias de Bakhtin para complementar a abordagem sociocultural, por julgar que, a partir delas, é possível examinar o funcionamento interpsicológico e intrapsicológico concreto sem perder de vista como este funcionamento se localiza em cenários históricos, culturais e institucionais. No centro da construção teórica de Bakhtin estão as ideias de voz, enunciado, gênero discursivo e linguagem social. A noção de voz, para Bakhtin, se aplica tanto à comunicação oral como à escrita, e abarca questões mais amplas do posicionamento do sujeito falante: seu horizonte conceitual, sua intenção e sua visão de mundo (WERTSCH, 1993). As vozes existem sempre em um ambiente social; não existe uma voz em total isolamento de outras vozes. A voz está inerentemente vinculada ao enunciado, pois é a voz que produz o enunciado. Portanto, não há enunciado neutro, sem refletir um ponto de vista, uma visão de mundo.

Para Bakhtin (2003), "o discurso sempre está fundido em forma de enunciado pertencente a um determinado sujeito do discurso e fora dessa forma não pode existir" (p. 274). Segundo o autor, os enunciados possuem as seguintes propriedades estruturais: os limites, que são dados pela troca dos falantes; a finalização, que indica a conclusão do enunciado; e a forma genérica, que diz respeito a um tipo estável de enunciado corrente em uma esfera de atividade social. As trocas adquirem diferentes formas nas esferas e atividades da vida social, dependendo das funções da linguagem e das condições e situações da comunicação, constituindo pares 
Apropriação discursiva do tema 'interdisciplinaridade' ...

de enunciados, tais como: pergunta-resposta; afirmação e objeção; afirmação e assentimento; sugestão e aceitação; ordem e execução.

A eleição de um gênero discursivo está determinada pela natureza específica de uma dada esfera da comunicação verbal, por considerações temáticas, pela situação concreta da comunicação verbal e pela composição pessoal dos enunciados (BAKHTIN, 2003). Em relação ao próprio falante, cada enunciado se caracteriza, antes de tudo, por um determinado conteúdo semântico de referência. O segundo elemento é seu aspecto expressivo, isto é, a relação subjetiva emocionalmente valorativa do falante, com o conteúdo e sentido do seu enunciado. Wertsch (1993) equipara o aspecto expressivo com a perspectiva sobre o conteúdo do enunciado que, para o autor, desempenha um papel importante no relacionamento interpsicológico na zona de desenvolvimento proximal, na medida em que diferentes perspectivas se enfrentam.

$\mathrm{Na}$ relação do enunciado com os outros participantes da comunicação verbal, a dialogicidade desempenha papel central. Para Bakhtin,

os enunciados não são indiferentes entre si, nem se bastam cada um a si mesmos; uns conhecem os outros e se refletem mutuamente uns aos outros. Cada enunciado é pleno de ecos e ressonâncias de outros enunciados com os quais está ligado pela identidade da esfera de comunicação discursiva e deve ser visto como uma resposta aos enunciados precedentes de um determinado campo: ela os rejeita, confirma, completa, baseiase neles, subentende-os como conhecidos, de certo modo os leva em conta. (BAKHTIN, 2003, p. 297)

Esta consciência e reflexão podem ocorrer de muitas maneiras: repetir o enunciado do outro; mencionar o enunciado do outro; pressupor em silêncio; expressar reação no nosso próprio discurso. Todas essas características estruturais que distinguem um enunciado do outro são critérios úteis para caracterizar um gênero discursivo. Para Bakhtin (citado por WERTS$\mathrm{CH}, 1993)$, a significação só pode chegar a existir quando duas ou mais vozes se põem em contato: quando a vOz de um ouvinte responde à voz de um falante. A noção de compreensão, para Bakhtin (2003), está intimamente relacionada à relação entre enunciados: "quando o ouvinte percebe e entende o significado da fala ele simultaneamente toma uma atitude ativa, responsiva em sua direção: concorda com ela, ou discorda dela, ou a aumenta ou a aplica, prepara para sua execução e assim por diante" (p. 271).

Considerando o horizonte social mais amplo do falante, seu discurso é sempre constituído a partir de uma linguagem social, isto é, "um discurso próprio de um estrato específico da sociedade (segundo a profissão, idade etc.) em um sistema social dado e um momento dado" (HOLQUIST e ERMERSON, citado por WERTSCH, 1993). Cada uma dessas linguagens exibe marcas que as diferenciam umas das outras, seja pela função, pelo conteúdo ou por um 'princípio sociodialetológico' (BAKHTIN, 1981). Qualquer que seja o princípio que as torne linguagens únicas, o plano que as unifica é que todas elas são pontos de vista específicos sobre o mundo, ou seja, formas de conceituar o mundo em palavras, visões de mundo, cada qual caracterizada por seus próprios objetos, significados e valores. Como um resultado desse processo de estratificação, não há palavras neutras no sentido de que não pertençam a ninguém.

O processo de elaboração de enunciados a partir de linguagens sociais foi comparado, por Bakhtin, à ventrilocução, fazendo alusão ao ato de falar através de outra voz. Esse concei- 
to enfatiza a ideia de que os falantes não escolhem suas palavras de uma linguagem neutra e impessoal, mas as retiram de contextos concretos e alheios. A apropriação se dá quando o falante marca essa linguagem com sua própria intenção, adaptando-a a sua semântica e visão de mundo.

Entretanto, não serão todas as palavras que se submeterão facilmente à apropriação por qualquer pessoa, podendo as mesmas permanecerem alheias ou soando como estrangeiras na boca de quem delas se apropriou, não sendo, assim, assimiladas ao novo contexto. Essa resistência das palavras se deve ao fato de que:

\footnotetext{
a linguagem não é um meio neutro que passa livremente e facilmente para a propriedade privada das intenções de um falante, ela é povoada - superpovoada - com as intenções de outros. Expropriá-la, forçando-a a se submeter a sua própria intenção e acentos, é um processo difícil e complicado. (BAKHTIN, 1981, p. 294)
}

Assim, linguagens diferentes podem coexistir na consciência das pessoas, contrapondo-se e interrelacionando-se dialogicamente. No meio social, não há como fugir à atividade de selecionar a linguagem adequada para determinado fim. Esse processo, em princípio inconsciente, pode se tornar consciente na medida em que o indivíduo comece a reconhecer as contradições entre as linguagens em termos de seus sistemas ideológicos e concepções de mundo. Neste momento, ele começa a necessitar de uma escolha ativa, resultante de sua própria orientação sobre elas. Essa formação ideológica é vista por Bakhtin (1981) como "o processo de seletivamente assimilar as palavras dos outros" (p. 341). Tanto o discurso autoritário quanto o internamente persuasivo participam deste processo, sendo o primeiro, o que exige apenas aceitação ou rejeição, e o segundo, aquele que procura por contrapalavras (palavras próprias do sujeito em resposta a palavras do outro), permitindo a interanimação dialógica.

Aos conceitos de Bakhtin, Wertsch (1993) propõe a metáfora da caixa de ferramentas, para colocar em evidência a diversidade de ferramentas culturais disponíveis aos indivíduos; e, a partir dessa idéia, utiliza a noção de heterogeneidade (TULVISTE, citado por WERTSCH, 1993), segundo a qual, em toda cultura e em todo indivíduo, não existe apenas uma forma homogênea de pensamento, mas tipos de pensamento verbal qualitativamente diferentes que produzirão gêneros discursivos distintos. Esses conceitos vão permitir colocar questões sobre a escolha (privilegiação), de um sujeito em particular, por um ou outro gênero discursivo. Essa abordagem permitirá uma aproximação sociocultural à ação mediada na medida em que se poderão compreender as diferenças culturais, históricas e institucionais na ação mental. Este enfoque também é importante porque se afasta da ideia de posse de determinadas formas de capacidade mental por determinados grupos, que têm sido questionadas por vários estudos recentes de psicologia evolutiva e outras áreas da investigação em ciências sociais (WERTS$\mathrm{CH}, 1993)$. O enfoque da ação mediada e da caixa de ferramentas, além de reconhecer o agente como o indivíduo que opera com instrumentos mediadores, leva ao questionamento sobre por que, em determinada ocasião, se emprega um gênero entre vários possíveis. 
Apropriação discursiva do tema 'interdisciplinaridade' ...

\section{Metodologia}

A presente pesquisa pode ser considerada como um estudo de caso que tem, como sujeitos, 12 licenciandos em Física (Lic1 a Lic12), duas professoras de Geografia (prof ${ }^{\mathrm{a}}$ G1 e prof $^{a}$ G2), duas professoras de Biologia (prof ${ }^{a}$ B1 e prof ${ }^{a}$ B2), duas professoras de Português ( prof $^{a}$ P1 e prof ${ }^{a}$ P2), um professor de Física (prof F) e uma professora de História (prof ${ }^{a} H$ ), todos participantes do curso a distância mencionado anteriormente. A discussão no fórum foi orientada pela tutora no início, quando apresenta o tema e indica caminhos para o seu desenrolar, e, no final, fazendo um balanço geral, procurando atualizar a discussão em relação à produção de conhecimentos na área da educação em ciências.

Os vinte participantes foram solicitados a ler os textos 1 e 2 (REZENDE e COLA, 2004; PIERSON e NEVES, 2001), que discutiam bases conceituais sobre o tema da interdisciplinaridade e um exemplo de sua aplicação na formação de professores das ciências. A leitura serviria como ponto de partida para a discussão no fórum e a reflexão sobre a situaçãoproblema ${ }^{4}$ do curso.

Nosso objeto de investigação foi um corpus composto por 63 mensagens enviadas por todos os participantes, ao fórum, ao longo de um período de duas semanas. É importante notar que o discurso a ser analisado não foi produzido em função de instrumentos de pesquisa, tais como entrevistas ou questionários, mas foram produzidos 'naturalmente' no espaço virtual do curso. Embora não haja o efeito da presença de pesquisadores no fórum do curso, sendo um espaço onde se estabelecem relações pedagógicas, é possível dizer que o discurso dos participantes é conformado por este 'contexto educativo' e que, portanto, as mensagens podem ser entendidas como respostas a ele.

Para se compreender a construção social de significados pelos participantes, foi feita a análise da atividade discursiva de modo a identificar os processos por meio dos quais os participantes se apropriam de linguagens sociais se deslocando do funcionamento interpsicológico para o funcionamento intrapsicológico. As mensagens enviadas ao fórum foram consideradas como enunciados dos participantes, tendo sido desconsideradas aquelas que tratavam apenas de aspectos operacionais (14 mensagens).

Em relação ao conteúdo semântico referencial dos enunciados, analisamos os movimentos de transformação que dizem respeito a apropriações do tema interdisciplinaridade, com ênfase: apenas na teoria, apenas na prática, ou ainda na sua integração. Quanto ao posicionamento dos falantes em relação aos seus próprios enunciados, analisamos seus pontos de vista

\footnotetext{
${ }^{4}$ Descrição da situação-problema: "Um grupo de professores de Ensino Básico, de várias séries e disciplinas diferenciadas, sensibilizados com a escolha de 100 anos do 14 BIS para ser o tema central da III Semana Nacional de Ciência e Tecnologia, divulgada e apoiada pelo Ministério de Ciência e Tecnologia em todo o Brasil, iniciou um trabalho de planejamento coletivo para ações didáticas, em cooperação com professores universitários. Para começar a planejar, procuraram tomar conhecimento do farto material relacionado ao tema divulgado pela mídia. Comprometidos com o assunto e com o objetivo de empreender ações para a sua realidade escolar, se depararam com a questão: Como desenvolver uma abordagem interdisciplinar do vôo para comemorar o centenário de Santos Dumont?"
} 
em relação ao tema. Quanto à relação dos falantes com os enunciados de outros, identificamos concordâncias e discordâncias entre os participantes. A profundidade dessa análise do discurso abre, assim, uma janela para a construção coletiva de conhecimento.

Respeitando-se a ordem cronológica em que foram emitidos, os enunciados foram agrupados em quatro episódios, não apenas em função de seus conteúdos, mas, sobretudo, em função do posicionamento do falante em relação ao conteúdo. Para identificar as vozes e as linguagens sociais dos participantes, foram usados os critérios de Bakhtin para caracterizar o enunciado, em particular os que concernem ao conteúdo semântico referencial, à relação do falante com o enunciado e à relação do falante com o enunciado de outros.

\section{A apropriação discursiva sobre interdisciplinaridade}

Esta seção apresenta a análise do discurso dos quatro episódios, destacando-se alguns enunciados escolhidos por terem sido considerados como os mais pertinentes para a discussão da questão de pesquisa.

\section{A interdisciplinaridade teórica na prática}

Este episódio caracteriza o início do fórum, com a coordenadora do curso e a tutora convidando a todos para uma troca de ideias sobre as possibilidades e limites da interdisciplinaridade na escola, com base na leitura do texto 1 na primeira semana e do texto 2 na segunda semana. A expressão 'troca de ideias', presente nos enunciados das duas professoras, pretende mostrar que elas entendem o fórum como possibilidade de promover o contato 'simétrico' entre diferentes vozes. Este contato ocorre em diferentes diálogos estabelecidos entre a tutora e os licenciandos e entre os licenciandos e os professores.

A tutora apresenta, então, o conteúdo semântico de referência como "um tema do qual muito se fala, mas pouco se faz: a interdisciplinaridade".

A Lic2, ao se apresentar, coloca a sua expectativa de aprender a trabalhar com temas interdisciplinares, o que poderia imprimir à discussão um caráter eminentemente instrumental. Entretanto, percebe-se um olhar mais profundo da questão quando o Lic4, a partir do texto 1, junta à prática, a reflexão sobre a necessidade de se abordar a realidade interdisciplinarmente:

Lic 4: "Em uma breve leitura que en fiz. no texto1 pude perceber uma das maiores vantagens de se trabalhar interdisciplinarmente: explicar o real. Como assim? Explicar o real, pois como sabemos, a natureza não é dividida em conteúdos formais/ disciplinados, mas sim constituida por uma rede complexa que enlaça as diversas formas de conhecimentos que foram desenvolvidas pelo homem; com esta divisão pretendese facilitar a compreensão de uma pequena faixa controlada por variáveis. Ai é que está o problema desta divisão, o nosso papel, como educadores, é de fornecer e desenvolver ferramentas que auxiliem nossos alunos a solucionarem problemas, a buscarem por informações quando estas thes faltarem, ou seja, que sejam capazes de proceder frente questões impostas pelo mundo. Outra coisa, embora a interdisciplinaridade seja um bom caminho, isto não quer dizer que seja o mais fácil." 
Apropriação discursiva do tema 'interdisciplinaridade' ...

No enunciado que o Lic4 dirige a todos, ouvem-se dois sistemas semânticos e axiológicos. Ele demonstra ter se apropriado do gênero discursivo acadêmico, quando sintetiza a ideia principal do texto 1 , mencionando que a interdisciplinaridade serve para explicar a realidade que é complexa e que não é dividida em conteúdos formais desenvolvidos pelo homem. $\mathrm{Na}$ continuidade, percebe-se a busca de integração da teoria com a prática na voz de um licenciando que já se vê como educador, validando o conhecimento acadêmico e mostrando a preocupação de fornecer e desenvolver ferramentas que evitem a divisão disciplinar e que possam auxiliar alunos a solucionarem problemas ou questões impostas pelo mundo. Entretanto, seu enunciado mostra também a tensão entre teoria e prática na medida em que, apesar de considerar a interdisciplinaridade um bom caminho, aponta para a possível dificuldade de se colocá-la em prática.

A apropriação do gênero discursivo acadêmico pelo Lic4 foi considerada adequada aos propósitos do curso pela tutora:

Tutora: "É isso aí, Lic4! Convém lembrar também que não se deve perder de vista que uma compreensão integrada do mundo não implica a dissolução das disciplinas e áreas do conbecimento estabelecidas na ciência, mas para alcançarmos essa compreensão é necessário que as disciplinas conversem e é isso que podemos começar a fazer ou intensificar nesse curso. A simplicidade das nossas aulas especificas precisa dar um espaço para a complexidade das explicações que queremos construir com nossos alunos."

Sua avaliação positiva ("É isso aí, Lic4") aponta o caminho a ser seguido pelos demais participantes. Em seguida, dirigindo-se a todos, ela conjuga o discurso acadêmico com o discurso escolar quando menciona a interdisciplinaridade no próprio curso e a possibilidade de exercê-la na escola, esclarecendo alguns aspectos que se relacionam ao enunciado do Lic4, como, por exemplo, a ideia de que não existe interdisciplinaridade sem disciplinas.

Após a fala da tutora, a discussão toma um rumo teórico quando a Lic5 aborda as classificações de termos relacionados com interdisciplinaridade, apresentadas no texto 1. Ela coloca uma questão retórica a si mesma, respondendo em seguida: "Dentre essas classificações, a interdisciplinaridade é a que tem se mostrado mais adequada, para ser usada no âmbito educacional? A 'transdisciplinaridade' é uma das três classificações feitas por Piaget, que a define como "a constituição de um sistema total e sem fronteiras sólidas entre as disciplinas". No decorrer de seu enunciado, ela dialoga com o Lic4, ao relacionar o conceito de 'rede complexa' utilizado por ele, à definição de transdisciplinaridade. A Lic5 demonstra apropriação do texto na medida em que sintetiza as formas de relação entre as disciplinas, estabelece novas relações e defende a transdisciplinaridade, que identifica com complexidade.

O enunciado do Lic6 traz, pela primeira vez no fórum, uma visão que põe em dúvida o valor da interdisciplinaridade para a prática pedagógica, até então não questionado.

Lic6: "Bem, algumas pessoas já deram suas opiniões defendendo a interdisciplinaridade, mas ninguém levantou questões contra ela. Acho que em um debate, é importante sempre termos os pontos positivos e negativos do assunto em questão, para assim podermos entendê-lo melhor, defendê-lo ou atacá-lo. [...] Acho que muitas pessoas estão achando que ela é fundamental para as práticas pedagógicas do futuro/presente, no entanto, eu acho que ela é apenas desejável." 
A professora $G 1$, que se expressa em seguida, não se preocupa com o argumento trazido por Lic6 e resume o texto 1, enumerando as principais ideias apresentadas pelos autores. Apesar de trazer a voz do texto, não a submete às suas próprias intenções, caracterizando apenas uma ventrilocução. Seu enunciado posterior parece mostrar sintonia entre a teoria que expõe e seu posicionamento em relação ao tema, já que ela relata uma prática interdisciplinar vivida em sua escola.

A professora relata uma experiência rica em interações entre a escola e outras instituições que proporcionaram uma série de ações de caráter interdisciplinar. Ela destaca vários aspectos positivos dessa experiência no que diz respeito à recepção pelos alunos e por alguns professores. Reconhece, contudo, que isso foi possível devido a condições particulares, talvez não compartilhadas por outras escolas, chamando atenção, assim, para empecilhos institucionais para se implementarem projetos desse tipo. Ela sintetiza essa excepcionalidade e a distância que percebe entre teoria e prática: 'sabe, a interdisciplinaridade ainda é um bicho papão, é bonita na teoria, mas na prática [...]'. Este comentário também explicita sua atitude em relação à teoria, concebendo-a como algo fechado que não se mistura com a prática.

No enunciado seguinte, a Lic5 volta a defender a transdisciplinaridade, considerandoa como uma etapa mais avançada que a interdisciplinaridade. Entretanto, concorda com a maior parte dos que a antecederam em explorar inicialmente a interdisciplinaridade, usando, como justificativa, o argumento do texto 1 de que essa abordagem seria uma demanda social. Nesse momento, seu enunciado demonstra apropriação do conteúdo teórico no contexto da prática, demonstrando, assim, um tipo de construção de significados bem diferente da ventrilocução da professora que a antecedeu.

Lic5: "Assim como a interdisciplinaridade é mais abrangente que a multidisciplinaridade, penso que a transdiciplinaridade seria o ápice da educação. Mas, aceito que em princípio busquemos explorar ao máximo as idéias que a interdisciplinaridade proporciona, para a seguir, atingirmos um novo patamar. Afinal como dizem Pierson e Neves (2001) 'a demanda pelo interdisciplinar não é meramente acadêmica ou um privilégio cientifico, mas acima de tudo uma demanda social' [...]."

Em resposta ainda ao Lic6, o Lic4 advoga pela interdisciplinaridade, alegando que sem ela no ensino atual estaríamos "completamente perdidos" na medida em que a situação é de total desestímulo entre professores e alunos e de alta evasão escolar. O discurso do Lic4 defende, portanto, a interdisciplinaridade como uma solução indispensável para os problemas atuais da educação.

\section{Vozes se colocam contra a teoria}

Este segundo episódio é marcado, inicialmente, por um posicionamento de um professor e de um licenciando contra a discussão sobre interdisciplinaridade propiciada pelo texto 1 , sendo finalizado pelo questionamento de um licenciando contra a pertinência de se falar em termos teóricos, advogando por busca de soluções exclusivamente práticas. Tais posicionamentos são intercalados por vozes que não dialogam com esse questionamento, ora argumen- 
Apropriação discursiva do tema 'interdisciplinaridade' ...

tando com enunciados sobre a prática interdisciplinar, ora com apropriações teórico-práticas.

O Prof F inicia o episódio, apontando sua discordância com as abordagens classificatórias da relação entre disciplinas, apresentadas no texto 1:

Prof F: "Multidisciplinar, interdisciplinar, transdisciplinar, pluridisciplinar, disciplinaridade cruzada, Ufa. Será que devemos subdividir em categorias um assunto que tem como objetivo justo o oposto?"

Seu enunciado encontra eco na avaliação apreciativa positiva de um licenciando:

Lic6: "Excelente sacada Prof F! Parece pura antitese".

Em seguida, a prof ${ }^{a} \mathrm{~B} 1$ traz a voz de uma revista dirigida a professores, no sentido de levantar vários questionamentos e dúvidas em relação à prática interdisciplinar (exagero, negligência na avaliação, prevalência de propósitos sociais sobre os didáticos, ausência da intenção de ensino de conteúdos). Partindo desse diagnóstico, mostra seu reconhecimento de que nos encontramos em fase de transição e que, por isso, justificam-se as dificuldades encontradas: o 'novo' assusta, a formação disciplinar é fragmentada, há dificuldade de se vencerem barreiras. Fica claro que ela concorda com o investimento na interdisciplinaridade, considerando-a um desafio. A professora finaliza descrevendo o exemplo de sua escola e apontando para a dificuldade de muitos professores, que não conseguem relacionar o tema do projeto interdisciplinar ao conteúdo a ser trabalhado em sua disciplina.

Em um enunciado que reflete sobre o andamento do fórum, Lic6 chama a atenção para a pouca interação entre as ideias colocadas pelos participantes. Traz, como exemplo, a ausência de respostas à crítica feita pelo Prof $\mathrm{F}$ à classificação das formas de relacionamento entre as disciplinas. O Lic6 considera que as pessoas estão mais interessadas em defender posições preestabelecidas do que em realmente discutir abertamente o tema. Sua meta-análise do fórum denuncia a falta de dialogia entre os enunciados dos participantes, o que impediria a construção compartilhada de significados.

$\mathrm{Na}$ sequência, o enunciado do Lic7 evidencia apropriação teórica na medida em que traz a experiência interdisciplinar no âmbito da prática de ensino de Física e de Biologia, descrita no texto 2, para justificar seu posicionamento em relação à interdisciplinaridade e defender esse tipo de trabalho com alunos de outras áreas na formação de professores. Expressa sua concordância em relação à necessidade de se discutirem as dificuldades da prática interdisciplinar, já levantadas pelo Lic6. O Lic7 demonstra apropriação teórico-prática quando transpõe a dificuldade de interação entre estudantes de disciplinas diferentes, apontada pelos autores do texto 2 , como sendo um dos problemas enfrentados para implementar a interdisciplinaridade nas escolas.

Talvez em função do comentário do Lic6 sobre a falta de respostas ao prof F, o Lic8, se juntando ao Lic6 e ao Prof F, se levanta contra o considerado 'exagero teórico' na classificação das relações entre disciplinas, dizendo não conseguir ver, no texto 1, a busca por soluções, mas a supervalorização do tema da interdisciplinaridade. Suas exclamações demonstram sua indignação: 
Rezende, F.; Queiroz, G. R. P. C.

Lic8: "Meu Deus! O que é isso?! Não entendo o objetivo de definir em tantas categorias o que de essencial não precisa de definição. A beleza de uma solução sensata está na simplicidade. Quem pensa em dificultar o caminho definindo bobagens ('multidisciplinaridade', 'transdiciplinaridade', 'pluridisciplinaridade', 'disciplinaridade cruzada') parece como os dogmáticos da antiga Inquisição, que com medo de que o povo tivesse acesso ao conhecimento dificultavam seu acesso tornando as coisas complicadas, dai o uso do latim... e tantas outras coisas. No texto não consigo ver uma busca de solução, mas uma tentativa de supervalorização do tema em si (e sem necessidade: perde-se tempo e gastam-se palavras). Posso parecer arrogante falando assim, mas esse é o mais sincero sentimento que essa leitura despertou em mim."

De início percebe-se que o licenciando dialoga com a visão de ciência trazida das ciências da natureza, que valoriza a simplicidade das teorias vencedoras de uma crise de paradigmas, estendendo-a à educação, num momento de busca de melhores caminhos. A comparação que o Lic8 faz entre o texto 1 e a Inquisição demonstra que ele vê a teoria enquanto um discurso autoritário, e evidencia, também, a distância que a linguagem teórica impõe à prática educativa. $\mathrm{Na}$ continuidade de seu enunciado, ele manifesta sua concordância em relação à promoção do intercâmbio com outras áreas, mas continua criticando o "impressionante contraste entre o que se pensa e se discute com a realidade que vivemos". No sentido de viabilizar as inovações educacionais, ele sugere que as mudanças incluam necessariamente a revisão de outros elementos, tais como: a avaliação, o projeto pedagógico e o vestibular.

A Lic9 concorda com a sugestão do Lic8, considerando-o fundamental. No caso da implementação da metodologia interdisciplinar na escola, chama atenção para o aspecto institucional, ao defender a ideia de que toda a escola, incluindo a direção, deve estar de acordo com as mudanças a serem implementadas. Ela traz um exemplo da prática de sua escola que mostra a possibilidade de um compromisso entre o currículo institucional e a implementação de um projeto interdisciplinar. Acrescenta ainda que, apesar dos projetos serem realizados à parte do currículo, os professores tentam sempre abordar os temas do projeto nas matérias trabalhadas em sala de aula.

Em seguida, o Lic8 se dirige a todos, reforçando seu argumento inicial contra a teoria e apelando veementemente a todos que parem de falar em termos teóricos e busquem soluções práticas.

Lic8: '[...] Realmente deveremos propor abertamente essa questão. É preciso parar de falar em termos teóricos e buscar soluçooes práticas. O que os amigos acham disso?"

\section{Conciliando teoria e prática}

Neste episódio, nove licenciandos e três professoras se manifestam a respeito da interdisciplinaridade, abordando pontos de vista teóricos e práticos. As vozes da tutora e dos autores dos artigos lidos são usadas pelos participantes para ressaltar os aspectos teóricos. Alguns licenciandos demonstram integrar teoria e prática, enquanto a professora se prende, nesse momento, só à teoria, enunciando a voz dos autores sem demonstrar apropriação, e 
Apropriação discursiva do tema 'interdisciplinaridade' ...

outras professoras trazem exclusivamente o gênero discursivo da prática. Talvez em resposta ao apelo do Lic8, a maioria relata experiências educacionais interdisciplinares bem-sucedidas. O Lic3 traz a relação da interdisciplinaridade com a vida profissional e o Lic6 não concorda que as metodologias interdisciplinares sejam indicadas para quaisquer situações de ensino.

O Lic10 inicia o episódio reconhecendo o papel dos conhecimentos teóricos e práticos sobre interdisciplinaridade quando julga muito importante o que foi dito, até então, sobre este tema, que ele define como 'intercâmbio entre disciplinas'. Apela à autoridade da voz da tutora para redefinir interdisciplinaridade, chamando atenção para o fato de que as disciplinas não perdem a identidade, e sim propiciam a abordagem de um mesmo tema por diversos ângulos, se aproximando, assim, das ideias trazidas pela tutora, no início do fórum. Ao trazer esta definição para a prática escolar, aponta soluções e possíveis dificuldades. Assim, aponta a pedagogia de projetos como possibilidade de inovação curricular e pergunta-se sobre a relação da interdisciplinaridade com outras instâncias educacionais - como o vestibular, os concursos públicos -, e com outros elementos da escola - como a direção e os livros didáticos -, que podem favorecer ou dificultar a implementação de novos modelos educacionais.

A Lic2 sintetiza o que apreendeu sobre o conceito de interdisciplinaridade no fórum e por meio de outras leituras (BORGES, 2007) para manifestar seu acordo em relação à prática interdisciplinar comentada pela Lic9, reforçando a sua importância na sala de aula, e não apenas em projetos escolares. O Lic11 se posiciona a favor do comentário da Lic2 e acrescenta a motivação dos alunos como uma outro aspecto positivo dessa prática.

Lic11: "Concordo com a Lic2. Através da interdisciplinaridade os alunos podem perceber que as disciplinas não existem isoladamente no mundo em que vivem e é também uma ótima maneira de ajudá-los a vivenciar o porquê dos estudos de ciência (seja na área bumana ou tecnológica). Quem nunca escutou de um aluno aquela celebre pergunta: "Mas por que que eu tenho que aprender isto? Eu não vou usar isto para nada...". Acredito que através da interdisciplinaridade podemos motivar os alunos a aprender determinado conteúdo e ampliar os seus horizontes culturais."

A Lic1 traz a discussão para a prática, concebendo a interdisciplinaridade como uma resposta a possíveis problemas pedagógicos, como a falta de interesse ou o baixo desempenho dos alunos. Dirige uma questão a todos sobre como implementar essa metodologia no cotidiano escolar submetido ao cronograma curricular.

O Lic12 se pronuncia também sobre a prática, ao responder à colocação do Lic8 sobre a necessidade de mudança do sistema educacional, lembrando que ela também depende de pequenas intervenções de professores em serviço ou de futuros professores.

O Lic10 demonstra novamente apropriação teórico-prática, mesclando, ao discurso sobre sua prática, a definição de interdisciplinaridade apresentada no texto 1 . Traz uma ideia nova para o fórum, ao apontar mudanças estruturais já em curso, como é o caso de alguns vestibulares, por exemplo, que vêm incorporando a ênfase no conhecimento integrado e interdisciplinar. O Lic10 considera essa tendência como uma necessidade da futura sociedade do conhecimento.

O Lic7 faz uma analogia entre a atual situação educacional e um momento de mudança de paradigma na história da ciência: 
Lic7: "Concordo com o colega (Lic12) que somos nós, a nova geração de professores que deve usar de sabedoria e perseverança a fim de com muita luta obter um resultado diferente. Aulas não tanto formais e projetos que buscam interagir com várias disciplinas são realidades em alguns lugares. A própria história da Ciência mostra que quando era desenvolvida uma nova teoria, ela sofria questionamentos e sérias dificuldades para ser aceita pelo meio científico e confirmada como a que mais responde as perguntas que the eram destinadas. Somente com perseverança, confirmação experimental e o tempo eram aceitas. Da mesma forma creio que irá ocorrer com as mudanças no ensino."

O Lic6 responde aos últimos enunciados dos colegas, questionando a validade da interdisciplinaridade. Propõe que seja feita pesquisa para que seja comprovada sua superioridade em relação aos métodos tradicionais. No entanto, admite sua dificuldade em acreditar na pesquisa educacional. A finalização do seu enunciado mostra que ele vê a interdisciplinaridade apenas como uma, entre várias outras possibilidades pedagógicas, e que não seria sempre a melhor opção.

Lic6: "Bem... [...] Eu concordo que deva ser feita muita pesquisa em ensino interdisciplinar para saber se realmente é uma proposta válida e mais interessante que a atual. Mas eu realmente não entendo como acreditar em certas pesquisas em ensino... desculpem-me, mas se tratando de seres humanos, acho meio complicado extrair regras, já que as variáveis são muitas e pouco controladas. [...] Eu acho que a interdisciplinaridade deva ser uma ferramenta de ensino e não uma regra de ensino[...] Acho que em alguns casos utilizar-se de interdisciplinaridade será tão bom quanto será ruim em outros."

Os enunciados seguintes, da prof ${ }^{a} \mathrm{P} 1$ e da prof ${ }^{a} \mathrm{~B} 2$, não interanimam com o enunciado do Lic6 e refletem estritamente a voz da prática, descrevendo tentativas de implementação de projetos interdisciplinares. A prof ${ }^{a} \mathrm{~B} 2$ atribui as dificuldades da prática inovadora aos problemas da formação fragmentária dos professores e, com isso, se identifica com a visão dos licenciandos.

Dirigindo-se ao Lic6, o Lic3 relaciona a interdisciplinaridade a contextos profissionais não escolares, supondo que a construção de aviões exija conhecimentos interdisciplinares, $\mathrm{o}$ que justificaria, portanto, o desenvolvimento, na escola, de projetos interdisciplinares. Em seguida, parecendo falar para si mesmo, se pergunta se a fabricação de um avião requer conhecimentos interdisciplinares ou, ainda, conhecimentos específicos, em decorrência do modo de produção (identificado por ele como fordismo) presente no sistema capitalista. À medida que responde, o Lic3 parece dar início a uma reflexão, contrapondo a disciplinaridade à interdisciplinaridade na esfera social do trabalho, e questionando se a demanda por essa abordagem viria do mundo do trabalho ou se se originaria de propostas educacionais inovadoras.

Lic3: '[...] Hum... É verdade, o mundo lá fora tem muito mais vagas para trabalhos de conbecimento específico do que interdisciplinar. Será que se for começado a trabalhar a interdisciplinaridade nas escolas isso pode se inverter? Ou será que esta onda de interdisciplinaridade é uma necessidade do mercado de trabalho?" 
Apropriação discursiva do tema 'interdisciplinaridade' ...

\section{Um tema emergente: as bases epistemológicas da pesquisa}

Neste episódio, a tutora se dirige a todos, fazendo um balanço das contribuições dos participantes à discussão. Nesta releitura do fórum, percebe a importância de se posicionar frente à desconfiança do Lic6 em relação à pesquisa em ciências humanas, comparada por ele, implicitamente, às ciências naturais, $\mathrm{O}$ licenciando responde, revendo sua posição inicial.

A tutora avalia como boa a participação de todos e extrai do conjunto de falas uma conclusão sobre a interdisciplinaridade na prática segundo a visão dos participantes. Apropriase da voz de uma licencianda para convencer os participantes do curso sobre a importância do planejamento para a realização de projetos interdisciplinares na escola.

Tutora: '[...] estou de volta e fiquei realmente feliz em ler as discussões; passei praticamente uma hora relendo tudo neste forum e no de apresentação. A participação da maioria está muito boa. Vemos que a interdisciplinaridade não é mais uma novidade para a maioria dos participantes porque muitos já estão vivenciando projetos em suas escolas e com isso vão trazendo argumentos que pode encorajar aqueles que ainda se sentem presos às contingências retrógradas que de fato existem e são bloqueios a serem furados por atividades inovadoras, lembrando que para começar precisamos ter em mente o que disse a Lic2 sobre o planejamento e a clareza dos objetivos procurados [...]”

Comentando o enunciado do Lic6 sobre a pesquisa em educação, a tutora, por meio do gênero discursivo científico, chama atenção para as condições psicológicas, sociais, econômicas e políticas da construção do conhecimento científico tanto nas ciências da natureza quanto nas ciências sociais, usando como argumento a autoridade da história da ciência. Esclarece, desse modo, a concepção equivocada do Lic6 de que a pesquisa em ensino devesse oferecer regras gerais.

Tutora: "A fala do Lic6 diferenciando de forma tão forte a pesquisa em ensino da pesquisa na ciência chamada dura [...] me dá a impressão que esses resultados tão precisos dos últimos não foram alcançados por seres humanos sujeitos a uma série de condições psicológicas, sociais, econômicas, politicas etc. A história da ciência está repleta de exemplos que apóiam o meu argumento. Assim, como no estudo dos sistemas educacionais complexos não se pode tirar regras deterministas capazes de prever resultados padronizados, uma vez que resultados inesperados emergem durante os processos educacionais deslanchados com objetivos iniciais que mudam ao longo do tempo, os sistemas físicos complexos estão sujeitos a flutuações a partir de condições iniciais que não podem ser (intrinsecamente) determinadas com precisão."

Em seguida, a tutora transpõe seu argumento para o campo educacional, mostrando a evolução das bases epistemológicas também nesse campo.

Tutora: "Lic6, você tem razão quanto às regras ou à ausência delas, mas o objetivo dos pesquisadores dessa área já deixou de ser este há pelos menos 30 anos. O behaviorismo "já era", estamos no construtivismo, pensando na participação das pessoas na 
Rezende, F.; Queiroz, G. R. P. C.

construcão do seu conbecimento, da sua visão de mundo e de como isso é compartilhado socialmente."

O Lic6 dirige-se à tutora, demonstrando compreensão responsiva ao contrapor suas próprias palavras, admitindo que estivesse 'desatualizado' em relação às concepções contemporâneas sobre a construção do conhecimento científico. Dirige-se, então, a todos, retratando-se pelas considerações anteriores sobre a pesquisa em Educação.

Lic6: "Tutora, É... en acho que minha cabeça é de alguém que vive na década de 50! Preciso me atualizar um pouco nos meus pensamentos, né? Eu estava com o pensamento de que eram regras que se queria tirarpara o uso da interdisciplinaridade. Obrigado por me colocar no rumo certo. Pessoal, lendo o que a tutora escreveu, eu fui obrigado a reler o que eu havia escrito e senti que talvez tenha sido desrespeitoso com os pesquisadores da área humana."

Reforçando o seu posicionamento, a tutora traz novo conteúdo temático referencial no sentido de mostrar a importância da reflexão sobre a visão de ciência no ensino de ciências e na formação dos professores, indicando obras de epistemólogos contemporâneos para aprofundamento.

Tutora: "A visão de ciência que separa de forma tão marcante as ciências da natureza das ciências sociais tem de fato sido assunto de debate partir da década de $1930 \mathrm{com}$ personagens marcantes como Karl Popper e Bachelard, tendo a partir da década de 1960 outros nomes importantes como Thomas Kubn, Lakatos, Laudan, Nancy Nerssessian etc, físicos, filósofos, psicólogos que buscaram na bistória da ciência seus argumentos. Nossa formação nos cursos de Física em geral nos faz ter essa visão que muitas vezes chega a ser ingênua, mas que talvez tenha sido a que fez. com que nos apaixonássemos por essa área ao nos fazer vislumbrar a possibilidade de um conbecimento tão verdadeiro e poderoso [...].”

\section{Discussão e conclusões}

Nesta seção sintetizamos os pontos relevantes da análise, em duas partes: na primeira, são abordadas possíveis relações entre a apropriação discursiva e as características tecnológicas do contexto discursivo. Na segunda, resume-se a trajetória das vozes dos participantes em relação aos textos lidos e discutem-se aspectos da apropriação discursiva do tema 'interdisciplinaridade', considerando-se, sobretudo, o embate entre gêneros discursivos.

\section{A apropriação discursiva em fórum eletrônico}

Com relação ao contexto tecnológico de produção do discurso, podemos tentar relacionar algumas características dos enunciados a restrições ou possibilidades do fórum eletrônico. A manifestação por escrito e o assincronismo, por exemplo, permitiram a emissão, por 
Apropriação discursiva do tema 'interdisciplinaridade' ...

parte de uma professora, de uma voz totalmente fundida com o texto, ao fazer um resumo minucioso e longo, como se fosse uma cópia. Essa suposição é razoável, especialmente se comparamos a possibilidade desse tipo de enunciado no fórum com a pouca probabilidade de que ele ocorresse em uma discussão presencial e síncrona.

As características do fórum podem ter propiciado a meta-análise do fórum enunciada pelo Lic6, muito pouco usual e provável em uma discussão presencial.

A situação não-presencial pode também ter permitido a expressão de resistência à pesquisa em Educação pelo Lic6, na medida em que pode ter sentido menos constrangimento e mais liberdade para emitir enunciados com perspectiva tão dissonante.

Observamos que houve mais diálogo entre os licenciandos, sendo poucos os enunciados trocados entre professores e licenciandos. Este aspecto da dinâmica discursiva do fórum mostrou que a construção coletiva do conhecimento entre professores em serviço e licenciandos não foi favorecida. Este resultado implica não tomarmos por garantidas as vantagens de intercâmbios de experiências nos processos formativos on-line. Entretanto, não é possível afirmar se a limitação se deve à ferramenta técnica ou à heterogeneidade do grupo, o que também poderia conformar processos formativos presenciais.

\section{A apropriação da teoria e prática interdisciplinares}

Partindo do princípio de que não podemos separar o discurso da personalidade que está falando ou da situação de fala (BAKHTIN, 1981), os resultados obtidos estão, naturalmente, relacionados ao contexto social e tecnológico (discussão on-line em um curso para docentes em formação inicial e continuada com a orientação de uma formadora da Universidade) no qual o discurso foi produzido. $O$ meio utilizado privilegiava a interação verbal e o grupo de participantes envolvia sujeitos de diferentes níveis de experiência profissional e, portanto, diferentes linguagens e sistemas axiológicos.

O fórum de discussão analisado foi idealizado para introduzir a perspectiva teórica como uma nova classe de conteúdo semântico referencial no repertório dos participantes do curso e, portanto, um gênero discursivo a ser integrado ao processo de formação.

No primeiro episódio, a tutora propõe uma troca de ideias sobre os textos, buscando uma aproximação simétrica com os participantes. Ao avaliar uma das primeiras mensagens enviadas ao fórum, ela mostra a direção da discussão, que se inicia pela integração de ideias provenientes da leitura à prática educativa. Apenas um licenciando questiona o valor da interdisciplinaridade na escola. Também se percebem enunciados restritos ao sentido do texto ou apenas relatos de experiências que não se apropriam da teoria.

No segundo episódio, um professor se apropria da teoria com a intenção de mostrar inconsistência entre a terminologia que categoriza - e, portanto, separa - diferentes formas de interação entre disciplinas e o próprio conceito de interdisciplinaridade. Dois licenciandos entram em sintonia com a voz desse professor.

No episódio seguinte, vários licenciandos se preocupam em ressaltar a harmonia entre uma interdisciplinaridade teórica e a realidade escolar: a inovação na escola é possível. Mesmo sem se pronunciar neste episódio, nota-se a influência da voz da tutora na composição dos enunciados de vários licenciandos. Em um deles, um licenciando mostra seu ceticismo em relação à pesquisa em educação. 
No último episódio a tutora avalia a discussão e a contribuição de todos e inicia um diálogo com o Lic6, que tem como tema os pressupostos epistemológicos da pesquisa científica. O licenciando explicita, em seguida, sua mudança de ponto de vista.

Considerando os quatro episódios, é possível dizer que todos os participantes se mostraram de acordo com a tese de que a prática da interdisciplinaridade é positiva e deve estar presente na escola, apesar de um licenciando colocar em dúvida a validade de sua aplicação generalizada ao ensino. Entretanto, foi possível observar que, de um modo geral, os discursos sobre interdisciplinaridade se elaboram a partir de diferentes relações teoria-prática. Quando os enunciados abordam apenas a teoria ou apenas a prática, tem-se harmonia. Quando a teoria é considerada na prática, é possível se identificarem tensões e conflitos na aproximação desses discursos.

Assim, uma professora assume o gênero discursivo da teoria, resumindo mecanicamente os textos. Outros licenciandos e professoras lançam mão do gênero discursivo do cotidiano da escola para relatarem experiências interdisciplinares bem-sucedidas. Em ambos os casos, não são levantados questionamentos ou dúvidas.

A apropriação que confronta a teoria dos textos com a prática é vista nos enunciados de vários licenciandos. Independentemente do posicionamento em relação à interdisciplinaridade na escola, os enunciados do Prof F, Lic6 e Lic8 mostram conflitos e desconfianças em relação à possibilidade de compatibilizar teoria - não só relativa à interdisciplinaridade - e realidade educacional. No discurso desses participantes foi possível observar a resistência ao poder persuasivo dos textos teóricos, quando questionaram a classificação dos tipos de relacionamento entre disciplinas, considerada desnecessária e mesmo inconsistente. Quando o Lic8 apelou para que os participantes parassem de pensar em termos teóricos, ficou claro que a resistência não se restringiu especificamente àquele texto, mas ao papel da teoria educacional frente à realidade.

Neste contexto, também chamou muita atenção o questionamento feito pelo Lic6, do valor da pesquisa no âmbito das ciências humanas. Por trás desse posicionamento, foi possível enxergar o conflito - ainda que não sustentado na epistemologia contemporânea, mas vivido concretamente nas instituições acadêmicas - entre as ciências naturais e humanas. Em ambos os casos, tornou-se evidente que esta última é pouco reconhecida por alguns licenciandos. Não é possível dizer, no limite deste estudo, se o licenciando simplesmente aquiesceu à autoridade da tutora ou se houve uma nova compreensão em resposta a ela. Vale ressaltar que o discurso de autoridade, assim como o discurso dialógico são vistos como polos de uma dimensão que, na prática, estão ligados íntima e dinamicamente, e que a tensão entre estes pelos são uma característica fundamental da construção de significados nas interações discursivas entre professores e estudantes (SCOTT et al., 2006).

Os resultados encontrados deixam um alerta para a formação inicial de professores de Física no sentido da necessidade de problematizar os diferentes significados atribuídos pelos licenciandos aos conhecimentos teóricos provenientes da pesquisa em Educação em Ciências. A exemplo da discussão das possibilidades de implementação de práticas interdisciplinares na escola, uma construção integrada formada na confluência das linguagens das ciências naturais e sociais precisaria ser articulada durante a formação dos professores. Esse resultado aponta para a necessidade de se investigarem aspectos educacionais, culturais, sociais e institucionais que possam favorecer a integração dos gêneros discursivos em processos formativos a distância ou presenciais. 
Apropriação discursiva do tema 'interdisciplinaridade' ...

\section{Referências}

BAKHTIN, M. Estética da criação verbal. Trad. Paulo Bezerra. 4. ed. São Paulo: Martins Fontes, 2003.

The dialogic imagination. Austin: University of Texas Press, 1981.

BORGES, T. Novos rumos para o laboratório escolar de Ciências. Coleção Explorando o Ensino - Física. Disponível em: <http:/ / portal.mec.gov.br> . Acesso em: 2 ago. 2007.

MURPHY, E. Recognizing and promoting collaboration in an online asynchronous discussion. British Journal of Educational Technology, Oxford, v. 35, n. 4, p. 421-431, 2004.

PIERSON, A.; NEVES, M. Interdisciplinaridade na formação de professores de ciências: conhecendo obstáculos. Revista Brasileira de Pesquisa em Educação em Ciências, Porto Alegre, v. 1, n. 2, p. 19-30, 2001.

PUNTAMBEKAR, S. Analyzing collaborative interactions: divergence, shared understanding and construction of knowledge. Computers \& Education, Amsterdam, v. 47, $\quad$ p. 332-351, 2006.

REZENDE, F.; COLA, C. S. D. Hipermídia na educação: flexibilidade cognitiva, interdisciplinaridade e complexidade. Ensaio - Pesquisa Em Educação em Ciências, Belo Horizonte, v. 6, n. 2, p. 1-11, 2004.

REZENDE, F. et al. InterAge: um ambiente virtual construtivista para a formação continuada de professores de Física. Caderno Brasileiro de Ensino de Física, Florianópolis, v. 20, n. 3, p. 372-391, 2003.

REZENDE, F.; OSTERMANN, F. Interações discursivas on-line sobre Epistemologia entre professores de Física: uma análise pautada em princípios do referencial sociocultural. Revista Electrónica de Enseñanza de las Ciencias, Vigo, v. 5, n. 3, p. 505-521, 2006.

SCHNETZLER, R. P. O professor de ciências: problemas e tendências de sua formação. In: .; ARAGÃO, R. M. R. (Orgs.). Ensino de Ciências: fundamentos e abordagens. Campinas: Unimep, 2000. p. 12-41.

SCHRIRE, S. Knowledge building in asynchronous discussion groups: Going beyond quantitative analysis. Computers \& Education, Amsterdam, v. 46, p. 49-70, 2006.

SHULMAN, L. S. Knowledge and teaching: foundations of the new reform. Harvard Educational Review, Harvard, v. 57, n. 1, p. 1-11, 1987.

VIGOTSKI, L. S. A construção do pensamento e da linguagem. São Paulo: Martins Fontes, 2001

WERTSCH, J. V. Voces de la mente, un enfoque sociocultural para el estudio de la acción mediada. Trad. A. Silvestri. Madrid: Visor, 1993.

. Computer mediation, PBL, and dialogicality. Distance Education, Armidale, v. 23, n. 1, p. 105-108, 2002. 
Rezende, F.; Queiroz, G. R. P. C.

Artigo recebido em novembro de 2008 e aceito em julho de 2009. 